\title{
Group Buying of Competing Retailers
}

\author{
Rachel R. Chen \\ Graduate School of Management, University of California at Davis, Davis, California 95616, USA, rachen@ucdavis.edu
}

Paolo Roma

Department of Manufacturing Technology, Production and Management Engineering, University of Palermo, Palermo, Italy, p.roma@dtpm.unipa.it

\begin{abstract}
$\mathrm{U}$ nder group buying, quantity discounts are offered based on the buyers' aggregated purchasing quantity, instead of individual quantities. As the price decreases with the total quantity, buyers receive lower prices than they otherwise would be able to obtain individually. Previous studies on group buying focus on the benefit buyers receive in reduced acquisition costs or enhanced bargaining power. In this paper, we show that buyers can instead get hurt from such cooperation. Specifically, we consider a two-level distribution channel with a single manufacturer and two retailers who compete for end customers. We show that, under linear demand curves, group buying is always preferable for symmetric (i.e., identical) retailers. For asymmetric retailers (i.e., differing in market base and/or efficiency), group buying is beneficial to the smaller (or less efficient) player. However, it can be detrimental to the larger (or more efficient) one. Despite the lower wholesale price under group buying, the manufacturer can receive a higher revenue. Interestingly, group buying is more likely to form when retailers are competitive in different dimensions. These insights are shown to be robust under general nonlinear demand curves, except for constant elastic demand with low demand elasticity.
\end{abstract}

Key words: group buying; competition; distribution channel; quantity discounts; retailing History: Received: January 2008; Accepted: December 2009, after 2 revisions.

\section{Introduction}

Under group buying (GB), quantity discounts are offered based on buyers' aggregated purchasing quantity, instead of individual purchasing (IP) quantities. As the price decreases with the total quantity, there exist positive externalities among buyers that allow them to obtain lower prices than they otherwise would be able to obtain individually. GB is widely used for both business-to-business (B2B) and business-to-consumer (B2C) transactions. In a B2B context, co-operatives of independent grocers, convenience stores, or retail hardware stores have long existed in the United States as well as in Europe. ${ }^{1}$ Purchasing consortia formed by independent companies are also common in procuring computers, office furniture, or utilities such as electricity and gas (Anand and Aron 2003). In some industries, such as food services and health care, group purchasing organizations have a dominant presence (Mitchell 2002). Sometimes buying groups are also formed to meet minimum order quantities imposed by sellers. Recently, the rapid development of information technology has enabled cooperation and transactions among geographically distributed firms, which open up opportunities for demand aggregation over a larger scale.

Most studies on B2B GB focus on the benefit buyers receive in reduced acquisition cost or enhanced bargaining power (Dana 2006). In this paper, we investigate situations where GB can be detrimental to buyers. Specifically, we examine the impact of competition on the formation of group purchase. Buying groups are often concerned with the potential conflict of interest when their members compete. In his survey of more than 100 firms, Hendrick (1997) reports that a majority $(60 \%)$ of the purchasing consortia have memberships consisting of noncompetitors only, whereas $10 \%$ are exclusively made up of direct competitors. Some firms consider joining a competitor not the right choice because "[they] do not want to help competitors." In fact, mistrust among competitors can be a major hurdle for some (online) buying consortia (Gray 2003).

Various mechanisms have been introduced to reduce competition between members, e.g., requiring that members operate in tightly defined individual territories (IGD Retailing Factsheets 2007). According to the Canadian Garden Centre Co-op, benefits from cooperation are possible because its members are not immediate competitors. Nevertheless, some rival companies do cooperate. PhotoFair Stores, a buying group with members throughout New Jersey and New York, was founded on the belief that it is beneficial to be helpful to competitors. In 2006, two of the main street supermarket rivals in United Kingdom, The Co-operative Group and Spar UK, joined forces in 
a buying alliance to pool volumes in targeted areas of own label products. Both firms stressed that they would remain independent and collaborate only in buying, while maintaining "healthy and friendly competition" (Grocer 2006). Thus, it remains unclear whether two competing firms should ever cooperate in purchasing.

In this paper, we consider a two-level distribution channel consisting of a single seller (manufacturer) who offers a quantity discount schedule and two retailers who compete in the final market by selling to end customers. The market starts with an equilibrium where the retailers act individually in deciding their purchase quantities (i.e., IP). We examine the retailers' decision of whether to purchase together (i.e., GB) in order to obtain lower wholesale prices.

Under GB, two effects influence retailers' profits: the cooperation effect through demand aggregation, and the competition effect in the final market. Depending on whether retailers are symmetric (i.e., identical) or asymmetric (i.e., differing in market base and/or efficiency), these effects influence retailers' profits differently. Using linear demand curves, we discover a number of insights concerning the preference of retailers on their purchasing strategies. For instance, both retailers prefer GB under no competition. This is consistent with the observation that cooperation within buying organizations is becoming increasingly popular in the public sector in particular, where there is almost no competition (Schotanus 2007). Under competition, symmetric retailers always prefer GB. While mild competition is clearly preferable under IP, symmetric retailers might enjoy higher profits under more intense competition when they group purchase. Also, a deeper discount from the manufacturer is not always beneficial for buyers who purchase individually. When retailers mainly differ in one dimension (i.e., market base or efficiency), GB is always attractive for the smaller (or less efficient) retailer. However, it can be detrimental to the larger (or more efficient) one. Also, the manufacturer can receive a higher revenue, despite the lower wholesale price under GB. Interestingly, GB is more likely to form when retailers are competitive in different dimensions. These insights are shown to be robust under general nonlinear demand curves, except for constant elastic demand with low demand elasticity. We also briefly examine the case of three retailers to shed light on the dynamics of GB of multiple competing retailers.

In practice, retailers often face the opportunity of group purchase. World Wide Retailer Exchange (WWRE.com), the premier integrated worldwide exchange community, promotes the idea of demand aggregation among its members, who are mostly large retailers (e.g., Kroger, Safeway, CVS, Walgreens, etc.). In Europe, purchasing consortia are well established for the retail sector (Zentes and Swoboda 2000). In Italy, the top five buying groups account for almost $84 \%$ of the food retail market (Kuipers 2005). In United States and Canada, with the majority of furniture coming from overseas, independent retailers who do not get on board with a buying group often find themselves having a hard time surviving (Heist 2008). Similarly, dealers of electronics and appliances start purchasing together as they realize that they cannot continue to purchase products via traditional distribution and remain competitive (Knott 2009).

Most buying groups claim that they can generate significant savings for their members. The appliance retailer Filco receives rebates of $4-6 \%$ of total purchases through its affiliation with the Selective Consolidated Dealers Co-Op. Members of Star furniture, a buying group based in Salem, Virginia, receive rebates on orders averaging $2-5 \%$, with some rebates reaching 10\% (Rauen 1992). However, not all retailers engage in GB. While this can be explained by coordination efforts or purchase timing required for GB, we show that competition could also deter cooperation. Thus, our study offers another possible explanation of why some retailers may not join group purchase.

To the best of our knowledge, this is the first paper that studies GB in a distribution channel. In particular, we fully characterize the competition between two retailers, with and without GB. Our study generalizes the existing knowledge on GB by considering a number of structure features: price-sensitive market demand, direct competition in the marketplace, and general quantity discount schedules. Results of this paper help managers to better understand the dynamics of cooperation in purchasing and provide guidelines for their decisions in a competitive environment. Although our model concerns the retailers, the framework developed here can be extended to other settings, such as GB of competing manufacturers.

The outline of the paper is as follows. A review of the relevant literature is presented in section 2 . We introduce the model and describe the equilibrium solutions in section 3, and present our results with discussions in section 4 . Section 5 considers two extensions: nonlinear demand curves and multiple retailers. Section 6 concludes.

\section{Literature Review}

Our paper is related to several research streams, including quantity discounts, competition in distribution channels, group buying, and inventory centralization games.

Quantity discounts have been extensively studied from one of three viewpoints: price discrimination (Buchanen 1953, Oi 1971), channel coordination (Jeuland and Shugan 1983, Ingene and Parry 1995, 1998, 
Raju and Zhang 2005), and operational efficiency (Crowther 1964, Dada and Srikanth 1987, Erhun et al. 2008, Monahan 1984). Some studies combine the last two streams by considering channel coordination with price-sensitive demand and operating costs (Chen et al. 2001, Weng 1995). Interested readers are referred to the reviews in Dolan (1987) and Weng (1995). Our work is close to the marketing literature on channel coordination. Jeuland and Shugan (1983) first discuss how quantity discounts could be used to maximize channel profits. Ingene and Parry (1995) introduce competing retailers to the quantity discount literature. Raju and Zhang (2005) study channel coordination in the presence of a dominant retailer. Similar to Ingene and Parry (1995), we consider a single manufacturer offering quantity discounts to competing retailers. However, our work focuses on the retailers' decision of whether to group purchase, whereas most papers in this area examine channel coordination. Moreover, we allow the discount to be based on the total quantity, instead of on the IP quantities as in most quantity discount studies.

In terms of competition in distribution channels, our work is closely related to Tsay and Agrawal (2000), who explore channel coordination when retailers compete in both price and service. They point out that, due to model complexity, typically deterministic formulations are found in most existing multi-echelon analyses that incorporate demand competition. Such models are common in economics (cf Katz 1989, Tirole 1988 for reviews) and marketing literature (e.g., Choi 1991, Coughlan and Wernerfelt 1989, Ingene and Parry 1995, 1998, McGuire and Staelin 1983, Moorthy 1987, Padmanabhan and Png 1997, Trivedi 1998). Our model also considers deterministic demands and price competition, but we focus on the impact of competition on retailers' GB decisions, which has not been studied before.

Many theoretical and empirical studies on buyer groups have emphasized enhanced buying power that justifies the formation of buyer co-operatives, buyer alliances, and horizontal mergers (e.g., Chipty 1995, Dana 2006, Horn and Wolinsky 1988, Inderst and Wey 2003, Marvel and Yang 2008). Recently, Chen et al. (2008) explore buyers' bidding strategy under different GB mechanisms in B2B exchanges. None of the work considers competition among buyers.

While buying groups usually involve a long-term relationship among buyers, recently developed webbased GB allows demand to dynamically aggregate online, so that price is set based on market-wide demand. With demand uncertainty, GB (similar to auctions) is a mechanism for price discovery. Anand and Aron (2003) provide a survey of web-based practices of GB, and compare it with posted pricing under uncertain demand. There is also a growing body of literature that concerns B2C GB (Chen et al. 2002, Kauffman and Wang 2002), in which demand uncertainty plays an important role. We consider retailers' routine purchase from the manufacturer, which involves little uncertainty.

Finally, our work is related to the literature on inventory centralization in a distribution system, in which multiple independent retailers take advantage of risk pooling in joint ordering under stochastic demand (Anupindi et al. 2001, Chen 2009, Hartman et al. 2000, Slikker et al. 2005). This stream of literature does not consider retailer competition, which is our focus.

\section{Model Set-up and Analysis}

Consider a two-level distribution channel where one manufacturer sells a homogeneous good to two independent retailers, who compete in the final market by selling to end customers. The manufacturer's unit wholesale price is decreasing in the purchase quantity (i.e., quantity discount). In the initial market equilibrium, each retailer acts individually in purchasing from the manufacturer (i.e., IP). The retailers then consider the option of purchasing together to obtain a lower wholesale price (i.e., GB). GB is possible only when both retailers agree to cooperate.

The retailers are indexed by $i \in\{1,2\}$ and $j=3-i$. Retailer $i$ 's demand, $q_{i}$, decreases with its own price $p_{i}$ and increases with the opponent's price $p_{j}$. We first consider a linear demand function

$$
q_{i}=A_{i}-p_{i}+\theta\left(p_{j}-p_{i}\right), \quad \theta \geq 0,
$$

where $A_{i}$ is the demand for retailer $i$ when both prices are set at zero and $\theta$ measures substitutability between the retailers. The above demand function can be derived from the aggregate consumer utility function (Lee and Staelin 2000, Shapley and Shubik 1969), and is common in economic and marketing literature (see Ingene and Parry 1995, McGuire and Staelin 1983, Tsay and Agrawal 2000). We extend our model to several common nonlinear demand functions in section 5 .

$A_{i}$ reflects the comparative advantage of retailer $i$ in terms of access to customers, due to factors such as location, loyalty, brand, or service. While $A_{i}$ captures retailers' differentiation in "market base," $\theta$ reflects their competition intensity. There is no competition when $\theta=0$. We also assume that retailer $i$ incurs an operational cost $c_{i}$ in procuring and selling each unit of the product. $c_{i}$ reflects the operational efficiency of retailer $i$. Thus, our study focuses on the difference in retailers' access to customers and operational efficiency, two common factors in the literature that examines competing retailers (e.g., Ingene and Parry 1995, Tsay and Agrawal 2000). 


\subsection{Quantity Discount Function (QDF)}

According to the Robinson-Patman Act, a common price menu must be offered to each buyer to preclude sellers "from giving different terms to different resellers in the same reseller class." We assume that the same price menu is offered under either individual or group purchase. This is a reasonable assumption if the manufacturer is selling to many retailers, and has no knowledge of, or any control over the retailers' decision regarding individual or group purchase.

Quantity discount schedules come in all shapes and sizes. In a recent study, Schotanus et al. (2009) derive a general continuous quantity discount function (QDF) that describes the underlying function of different discount schedules. Under the QDF, the unit wholesale price $w(q)$ is

$$
w(q)=a+d / q^{e}
$$

where $a \geq 0$ is the base price, $d$ is the discount scale, and $e$ is the steepness. They show that this QDF fits well with 66 discount schedules found in practice, with $e$ varying from -1.00 to 1.60 .

Note that $d e>0$ is required to ensure that the unit wholesale price $w(q)$ decreases with $q$. The higher the discount scale $d$, the higher the wholesale price. When $e>0, \quad a=w(\infty)$ represents the minimum price, whereas $d=w(1)-w(\infty)>0$ reflects the price spread of the schedule. When $e<0$, we have $d<0$, and $a=w(0)$ is the maximum price. The absolute value of the discount scale, $|d|$, reflects how fast $w(q)$ decreases with $q$ and is referred to as the discount level. The higher the $|d|$, the more effective the demand aggregation by the retailers.

In general, quantity discounts are deep for the initial quantities and become flat as $q$ gets large. Thus, we assume $w(q)$ is convex, which requires $e \geq-1$. Also for total cost, $T C(q)=a q+d q^{1-e}$, to be concave in $q$, we need $e \leq 1$. Hence, we restrict to $e \in[-1,1]$, a range consistent with the empirical findings (Schotanus et al. 2009). Note that $T C(q)$ is nondecreasing in $q$ if $e>0$. For $e<0$, we follow Schotanus et al. (2009) by assuming $q \leq((-1+e)$ $d / a)^{1 / e}$ so that $T C(q)$ is increasing and $w(q)$ remains nonnegative. We also assume that retailers do not engage in any resale of the manufacturer's product. Then under an increasing and concave total cost function, no retailer will purchase more than what he can sell in the final market.

When the steepness $e=1, w(q)=a+d / q$ and the price schedule is in fact a two-part tariff, where the retailers share a lump-sum fee $d$ and incur a unit price $a$. When $e=-1, w(q)=a+d q$ with $d<0$, and the unit wholesale price linearly decreases with quantity $q$. Schotanus et al. (2009) report that five out of the 66 schedules collected have a steepness of -1 . This discount format is also common in the literature (Ingene and Parry 1995, 1998, Rosenblatt and Lee 1985, Tsai 2007). We assume $e \neq 0$, as $e=0$ is the trivial case of no
Figure 1 Range of Discount Scale and Steepness of the Quantity Discount Function

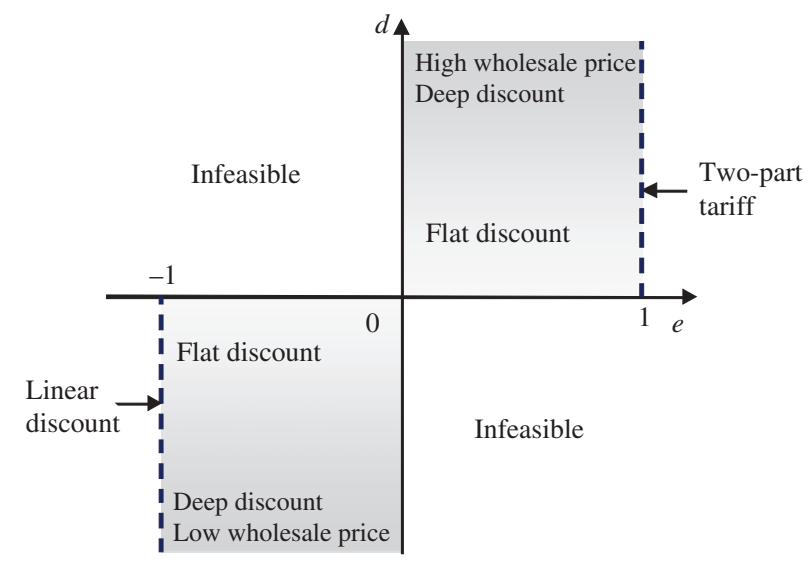

When $e>0$, a higher $d$ means a deeper discount but also a higher wholesale price. When $e<0$, a lower $d$ means a deeper discount and a lower wholesale price.

discount. Figure 1 depicts the possible range of discount scale and steepness of the general QDF.

We assume that each retailer pays the same unit wholesale price determined by the total quantity under group purchase, referred to as uniform cost allocation (Chen and Yin 2008). Such a payoff scheme is easy to calculate, achieves budget balance (i.e., the total payments equal the total cost $T C(q))$, and hence is appealing to the practitioners. For example, eWinWin.com, a major online GB facilitator, uses this rule to allocate the total cost after demand is aggregated through its online platform. To focus on the effects of competition, we make the common assumption that all model parameters are deterministic and common knowledge (e.g., Choi 1991, Ingene and Parry 1995, 1998, Jeuland and Shugan 1983, McGuire and Staelin 1983, Tsay and Agrawal 2000). For ease of exposition, we assume zero coordination cost under group purchase (which might involve administrative efforts such as phone calls or faxes). Such a (fixed) coordination cost is likely to result in a threshold policy, so the assumption can be easily relaxed without affecting our results qualitatively.

\subsection{Individual Purchasing}

We start with the initial market equilibrium where, given the discount schedule, each retailer acts individually in deciding its own retail price and purchase quantity. Under IP, retailer $i^{\prime}$ s wholesale price, $w\left(q_{i}\right)$, depends on its own purchasing quantity $q_{i}$. With a per unit operating $\operatorname{cost} c_{i}$, retailer $i^{\prime}$ s profit function is

$$
\Pi_{i}=\left(p_{i}-c_{i}-w\left(q_{i}\right)\right) q_{i} .
$$

Taking the first-order derivative with respect to $p_{i}$ and setting it to 0 yield

$$
\begin{aligned}
\frac{\partial \Pi_{i}}{\partial p_{i}} & =\left[1+(1+\theta) w^{\prime}\left(q_{i}\right)\right] q_{i}-\left(p_{i}-c_{i}-w\left(q_{i}\right)\right)(1+\theta) \\
& =0 .
\end{aligned}
$$


Table 1 Equilibrium Solutions under Individual Purchasing $(e=-1$ and 1$)$

\begin{tabular}{lll}
\hline & Linear schedule $(e=-1)$ & Two-part tariff $(e=1)$ \\
\hline Retailer price & $p_{i}^{I P-I}=\frac{A X+a+c}{X+1} \pm \frac{\Delta A X+\Delta c}{(1+2 \theta) X+1}$ & $p_{i}^{I P-t}=\frac{A+(a+c)(1+\theta)}{2+\theta} \pm \frac{\Delta A+\Delta c(1+\theta)}{2+3 \theta}$ \\
Retailer quantity & $q_{i}^{I P-I}=\frac{A-c-a}{X+1} \pm \frac{\Delta A-\Delta c(1+2 \theta)}{(1+2 \theta) X+1}$ & $q_{i}^{I P-t}=\frac{(A-c-a)(1+\theta)}{2+\theta} \pm \frac{\Delta A(1+\theta)-\Delta c(1+2 \theta)(1+\theta)}{2+3 \theta}$ \\
Total quantity & $Q^{I P-I}=2 \frac{A-c-a}{X+1}$ & $Q^{I P-t}=2 \frac{(A-c-a)(1+\theta)}{2+\theta}$ \\
Retailer profit & $\Pi_{i}^{I P-I}=(X-d)\left(q_{i}^{I P-I}\right)^{2}$ & $\Pi_{i}^{I P-t}=\frac{\left(q_{i}^{\mid P-t}\right)^{2}}{1+\theta}-d$ \\
\hline
\end{tabular}

Sign $+(-)$ is associated with retailer $1(2) . X \doteq \frac{1}{1+\theta}+2 d$.

Maximizing (3) with respect to $p_{i}$ and jointly solving for both retail prices yield the equilibrium price $p_{i}^{I P}$, $i=1$, 2. Closed-form solutions for $p_{i}^{I P}$ exist for $e=2,1$, $0,-1$, and -2 only. As we focus on $e \in[-1,1]$, we obtain the solution for $e=1$ and -1 (see Table 1), and explore the system behavior for other values of $e$ through numerical studies.

To focus on the impact of competition, we impose a number of conditions on the parameters to ensure a reasonable model with duopoly equilibrium under both IP and GB (e.g., nonnegativity of prices, quantities, and profits for both retailers). ${ }^{2}$ For the analysis of $e=-1$ and 1 , these conditions are explicitly described in (30)-(34) and (36)-(38) in the supporting information Appendix $\mathrm{S} 1$. For general steepness of $e$, we restrict our numerical analysis to the range where these conditions hold.

Substituting $p_{i}^{I P}$ into (1) yields the equilibrium quantity $q_{i}^{I P}$. The total quantity is $Q^{I P}=q_{1}^{I P}+q_{2}^{I P}$, and the manufacturer's revenue under IP is

$$
R^{I P}=w\left(q_{1}^{I P}\right) q_{1}^{I P}+w\left(q_{2}^{I P}\right) q_{2}^{I P} .
$$

By (3) and (4), retailer $i$ 's equilibrium profit under IP, $\Pi_{i}^{I P}$, can be written as

$$
\Pi_{i}^{I P}=\left[\frac{1}{1+\theta}-\frac{d e}{\left(q_{i}^{I P}\right)^{e+1}}\right]\left(q_{i}^{I P}\right)^{2}, \quad i=1,2 .
$$

Define $A \doteq \frac{A_{1}+A_{2}}{2}$ and $\Delta A \doteq \frac{A_{1}-A_{2}}{2}$ such that $A_{1}=$ $A+\Delta A$ and $A_{2}=A-\Delta A$. Similarly, let $c \doteq \frac{c_{1}+c_{2}}{2}$ and $\Delta c$ $\doteq \frac{c_{1}-c_{2}}{2}$ such that $c_{1}=c+\Delta c$ and $c_{2}=c-\Delta c . \Delta A$ and $\Delta c$ reflect the level of asymmetry between the retailers, with which we can write the equilibrium solutions for $e=1$ and -1 as in Table 1 . Note that $\Delta A$ and $\Delta c$ are not restricted to be positive. The superscripts $l$ and $t$ denote linear schedules and two-part tariffs, respectively.

For each retailer, while a larger market base $A$ is always beneficial, a higher operational cost $c$ or base price $a$ will be detrimental. Thus, $A-c-a$ reflects the environment in which retailers operate, and remains positive throughout the paper. As seen in Table 1, a higher $A-c-a$ leads to higher quantity and profit under IP. Note that $Q^{I P}$ does not depend on $\Delta A$ or $\Delta c$ under either linear discounts or two-part tariffs. Later we will show that, for the general QDF, the total quantity under IP decreases with the level of asymmetry.

\subsection{Group Buying}

We now consider the option of cooperation in purchasing between the retailers. Under $\mathrm{GB}$, each retailer $i$ 's wholesale price, $w(Q)$, depends on the total purchasing quantity, $Q=q_{i}+q_{j}$. The profit function of retailer $i$ is

$$
\Pi_{i}=\left(p_{i}-c_{i}-w(Q)\right) q_{i} .
$$

Taking the first-order derivative with respect to $p_{i}$ and setting it to 0 yield

$$
\begin{aligned}
\frac{\partial \Pi_{i}}{\partial p_{i}} & =\left(1+w^{\prime}(Q)\right) q_{i}-\left(p_{i}-c_{i}-w(Q)\right)(1+\theta) \\
& =0 .
\end{aligned}
$$

Maximizing (7) with respect to $p_{i}$ and jointly solving for both retail prices yield the equilibrium price $p_{i}^{G B}$ $i=1$, 2. Again, closed-form solutions exist for $e=2,1$,

\begin{tabular}{|c|c|c|}
\hline & Linear schedule $(e=-1)$ & Two-part tariff $(e=1)$ \\
\hline Retailer price & $p_{i}^{G B \_l}=\frac{A Y+a+c}{Y+1} \pm \frac{\Delta A(Y-2 d)+\Delta C}{(1+2 \theta)(Y-2 d)+1}$ & $p_{i}^{G B_{-} t}=A-\frac{Q^{G B_{-} t}}{2} \pm \frac{[\Delta A+\Delta c(1+\theta)]\left(Q^{G B_{-} t}\right)^{2}-d \Delta A}{\left(Q^{G B_{-} t}\right)^{2}(2+3 \theta)-d(1+2 \theta)}$ \\
\hline Retailer quantity & $q_{i}^{G B \_l}=\frac{A-c-a}{Y+1} \pm \frac{\Delta A-\Delta c(1+2 \theta)}{(1+2 \theta)(Y-2 d)+1}$ & $q_{i}^{G B_{-} t}=\frac{Q^{G B_{-} t}}{2} \pm \frac{[\Delta A-\Delta C(1+2 \theta)](1+\theta)\left(Q^{G B_{-} t}\right)^{2}}{\left(Q^{G B \_t}\right)^{2}(2+3 \theta)-d(1+2 \theta)}$ \\
\hline Total quantity & $Q^{G B_{-} I}=2 \frac{A-C-a}{Y+1}$ & $Q^{G B_{-} t}=\frac{(A-c-a)(1+\theta)}{2+\theta}+\left[\left(\frac{(A-c-a)(1+\theta)}{2+\theta}\right)^{2}-\frac{d(1+2 \theta)}{2+\theta}\right]^{1 /}$ \\
\hline Retailer profit & $\Pi_{i}^{G B \_l}=(Y-2 d)\left(q_{i}^{G B \_}\right)^{2}$ & $\Pi_{i}^{G B_{-} t}=\frac{\left(q_{i}^{G B_{-} t}\right)^{2}}{1+\theta}\left[1-d\left(Q^{G B_{-} t}\right)^{-2}\right]$ \\
\hline
\end{tabular}
$0,-1$, and -2 , but we will obtain the results for $e=1$ and -1 only (see Table 2 ). We then obtain the corresponding quantity $q_{i}^{G B}$ by substituting $p_{i}^{G B}$ into (1).

Table 2 Equilibrium Solutions Under Group Buying (e=-1 and 1)

$\operatorname{Sign}+(-)$ is associated with retailer $1(2) . Y \doteq \frac{1+d}{1+\theta}+2 d$. 
The manufacturer's revenue under GB is given by

$$
R^{G B}=w\left(Q^{G B}\right)\left(q_{1}^{G B}+q_{2}^{G B}\right) .
$$

From (7) and (8), we can write retailer $i$ 's equilibrium profit under GB as

$$
\begin{gathered}
\Pi_{i}^{G B}=\left(\frac{1}{1+\theta}\right)\left(1-\frac{d e}{\left(Q^{G B}\right)^{e+1}}\right)\left(q_{i}^{G B}\right)^{2}, \\
i=1,2 .
\end{gathered}
$$

Table 2 summarizes the equilibrium solutions for $e=1$ and -1 under GB.

\section{Comparison of IP and GB}

In this section, we compare the two models (IP and GB) for each retailer in order to find, if they exist, the conditions making cooperation in the form of GB suitable in a competitive environment. We first analyze the case of symmetric retailers (i.e., $A_{i}=A_{j}$, $c_{i}=c_{j}$ ). This is an important case because many buying groups consist of members of similar sizes, while it is unclear how competition affects their purchasing and pricing decisions. For differentiated retailers, we focus on their differences in access to customers and operational efficiency represented by market base and unit operational cost, respectively. We first explore retailers' decisions under asymmetry in the market base, assuming that they have the same operational costs (i.e., $\Delta A \neq 0, \Delta c=0$ ). For the case of asymmetry in efficiency (i.e., $\Delta A=0, \Delta c \neq 0$ ), the results do not differ qualitatively. The general case with asymmetry in both dimensions (i.e., $\Delta A \neq 0, \Delta c \neq 0$ ) is discussed at the end.

\subsection{Symmetric Retailers}

For symmetric retailers, at the equilibrium we have $p_{i}=p_{j}$ under either IP or GB. Under the general QDF, we have $w\left(q_{i}\right)=a+d / q_{i}^{e}$, with which we can simplify the first-order condition (FOC) under IP (4) as

$$
A-c-a=\frac{2+\theta}{1+\theta} q_{i}+\frac{d}{q_{i}^{e}}(1-e), \quad i=1,2 .
$$

Similarly, under GB we have $w(Q)=a+d / Q^{e}$, so that the FOC (8) becomes

$$
\begin{gathered}
A-c-a=\frac{2+\theta}{1+\theta} q_{i}+\frac{d}{2^{e+1} q_{i}^{e}}\left(2-\frac{e}{1+\theta}\right), \\
i=1,2 .
\end{gathered}
$$

Although closed-form solutions do not exist for general steepness $e$, we obtain several results for symmetric retailers based on Equations (11) and (12).

Proposition 1 (Effect of competition intensity). When the retailers are symmetric, a higher competition level $\theta$ leads to lower retail price and higher demand under both IP and GB, as well as lower profit under IP. However, under
$G B$ retailer profit will increase with $\theta$ when $(A-c-a) e>2 q_{i}^{G B}(\theta+e+e \theta) /(1+2 \theta)$. That is, more intense competition can result in higher retailer profit un$\operatorname{der} G B$.

See the supporting information Appendix S1 for proofs of all the propositions.

Results on how retail price and demand quantity change with $\theta$ are intuitive. Basically, competition exerts downward pressure on retail prices, so that demand quantities increase with $\theta$. Conventional wisdom suggests that firms prefer less intense competition, as confirmed by the result that retailer profit decreases with $\theta$ under IP. However, under GB retailer profit will increase with $\theta$ when $(A-c-a) e>$ $2 q_{i}^{G B}(\theta+e+e \theta) /(1+2 \theta)$. For $e=1$ (two-part tariffs), this condition can be reduced to $d>(A-c-a)^{2} \theta /$ $(1+2 \theta)$, so retailer profit increases with competition for deep discount (high $d$ ) and low competition (small $\theta$ ). For $e=-1$ (linear discount), we have $d<0$ and the condition is reduced to $|d| \geq 1 / 2$ or $\theta \leq|d| /$ $(1-2|d|)$. For general steepness $e$, numerical investigation confirms that this result holds for deep discount (high $|d|$ ) and mild competition (low $\theta$ ). Figure 2 depicts how retailer profit under GB changes with $\theta$ for positive steepness of $e$, where $\Pi_{i}^{G B}$ increases with $\theta$ for $\theta$ small. The result for negative steepness is similar.

Retailer competition in general leads to higher demand in the final market, and consequently lower unit wholesale price under the manufacturer's quantity discount. Under deep discount and mild competition, this effect is strengthened through group

Figure 2 Group Buying Profit Changes With Competition Level $\theta(A=1$, $c=0.1, a=0.3, d=0.1, e>0$ )

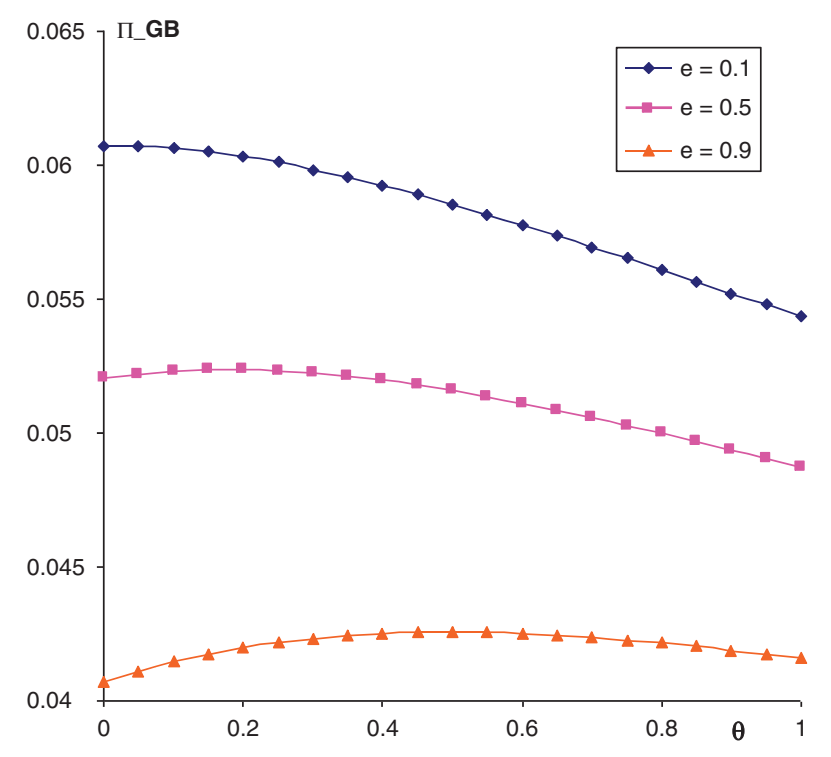


purchase so that each retailer's profit increases with competition level $\theta$. However, when the discount is not significant or competition is already fierce, a more intense competition will further depress retail prices and lower profits, passing most benefits on to consumers. This possibly explains the present situation of German grocery buying groups. In the food retail sector in Europe, buying groups are able to obtain significant discounts from suppliers. However, Germany is known for its fierce competition in food retailing, and such discounts are passed on to final consumers in lower prices. By contrast, competition among grocery retailers is much less intense in France, United Kingdom, and Spain (Dobson Consulting 1999).

Proposition 2 (Effect of discount scale). When retailers are symmetric, a higher discount scale d leads to higher retail price and lower demand under both IP and GB, as well as lower profit under GB. However, under IP retailer profit will increase with $d$ when $(A-c-a) e$ $>2 q_{i}^{I P}(1+e+e \theta) /(1+\theta)$. This implies that retailers can get hurt from a lower wholesale price with deeper discount under IP.

As shown in Figure 1, the higher the discount scale $d$, the higher the unit wholesale price $w(q)$. This in general leads to higher retail price and lower retail demand/profit, as is the case under GB. Under IP, retailer profit also decreases with $d$ under two-part tariffs $\left(\partial \Pi_{i}^{I P}-t / \partial d=-1<0\right.$ for $\left.e=1\right)$. However, for linear discount schedules $(e=-1)$, a lower discount scale $d$, or equivalently, a deeper discount level $|d|$, can result in a lower retailer profit. In fact, for $e=-1$, the condition $(A-c-a) e<2 q_{i}^{I P}(1+e+e \theta) /(1+\theta)$ can be reduced to $d \leq \frac{\theta-2}{2(1+\theta)}$, which will hold when $d$ is sufficiently low. This is because a fairly deep discount can introduce very low retail prices that essentially intensify retailers' competition.

For general values of $e$, numerical studies show that retailer profit under IP decreases with $d$ for $e>0$. For negative $e$ close to -1 , retailer profit can increase with $d$, as illustrated in Figure 3. For negative $e$ close to 0, retailer profit again decreases with $d$ under mild competition, although the result might reverse when competition is sufficiently high. In reality, the discount level varies across industries. For the optical buying group $\mathrm{ADO}$, the discount percentage for various eyewear models goes from 3\% up to 30\%. Proposition 2 suggests that retailers may not always prefer deeper discounts under IP. Interestingly, this never happens under GB, probably because the cooperation in purchasing helps soften the competition when discounts are deep. In fact, for symmetric retailers, the cooperation effect will dominate the competition effect and GB is always preferable, as shown in the next proposition.
Figure 3 Individual Purchasing Profit Changes With Discount Scale d $(A=1, c=0.1, a=0.3, \theta=2, e<0)$

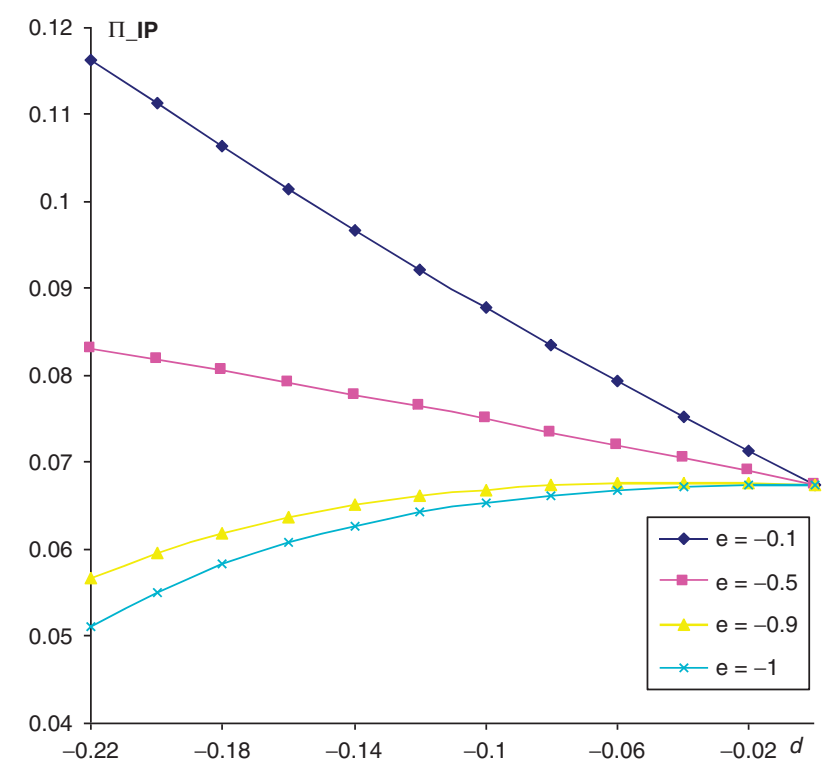

Proposition 3 (Comparison between IP and GB). With symmetric retailers, retail quantity (price) will be higher (lower) under $G B$ if $\theta<\widehat{\theta}$, with $\widehat{\theta}=e /\left[2-2^{e+1}(1-e)\right]-1$. Retailer profit is always higher under $G B$ with a lower unit wholesale price. However, it is possible for the manufacturer to have higher revenue under GB.

Although retailers are able to get a lower unit wholesale price under GB, they do not necessarily purchase more. As a result, the total quantity is not always higher under GB. When $\theta>\widehat{\theta}$, the fierce competition pushes each retailer to over purchase in order to qualify for a deeper discount under IP. Under GB, since the discount is based on aggregated demand, each retailer might scale back and buy less, resulting in higher retail prices in the final market. That is, retailers' cooperation might hurt end consumers. ${ }^{3}$ In particular, when $e=1$, we have $\widehat{\theta}=-1 / 2$, so demand quantity is always lower under GB $\left(q_{i}^{G B} \leq q_{i}^{I P}\right)$ for twopart tariffs. However for $e=-1$, we have $\theta=\infty$, so quantity is always higher under $\mathrm{GB}\left(q_{i}^{G B} \geq q_{i}^{I P}\right)$ for linear discounts.

For profit comparison, the message is more consistent. GB avails a deeper discount based on the total quantity, and effectively improves each retailer's profit. Thus, symmetric retailers who face fierce competition might consider cooperation as a mechanism to soften competition and improve profits. This is consistent with the observation that, while buying groups operate in various industries, they are most active in competitive retailing businesses such as appliances, jewelry, and consumer electronics (Rauen 1992). Table 3 summarizes the comparison for symmetric retailers. 
Table 3 Comparison between Individual Purchasing and Group Buying (Symmetric Retailers)

\begin{tabular}{llll}
\hline & \multicolumn{2}{c}{ Retailers } & \multicolumn{2}{c}{ Manufacturer } \\
\hline Retailer price & $p_{i}^{I P}>p_{i}^{G B}$ if $\theta<\widehat{\theta}$ & Unit wholesale price & $w\left(q_{i}^{I P}\right)>w\left(2 q_{i}^{G B}\right)$ \\
Retailer quantity & $q_{i}^{I P}<q_{i}^{G B}$ if $\theta<\widehat{\theta}$ & Total quantity & $Q^{I P}<Q^{G B}$ if $\theta<\widehat{\theta}$ \\
Retailer profit & $\Pi_{i}^{G B} \geq \Pi_{i}^{I P}$ & Revenue & $R^{I P} \lesseqgtr R^{G B}$ \\
\hline
\end{tabular}

In general, GB leads to a lower unit wholesale price and consequently a lower revenue for the manufacturer. In fact, this is always the case under two-part tariffs. However, for linear quantity discount schedules, if the base price $a$ is above certain threshold $a_{0}$ (see proof in the supporting information Appendix S1 for details), the manufacturer will receive a higher revenue when retailers cooperate. To see this, recall that $R^{I P}=2 q_{i}^{I P} w\left(q_{i}^{I P}\right), \quad R^{G B}=2 q_{i}^{G B} w\left(2 q_{i}^{G B}\right), \quad q_{i}^{I P}<q_{i}^{G B}$, and $w\left(q_{i}^{I P}\right)>w\left(2 q_{i}^{G B}\right)$ under linear discounts. When base price $a$ increases, both $q_{i}^{G B}$ and $q_{i}^{I P}$ are decreasing, which leads to higher wholesale prices. However, this impact is reinforced under GB because $w\left(2 q_{i}^{G B}\right)$ linearly decreases with the total quantity $2 q_{i}^{G B}$, resulting in a reduced gap between $w\left(q_{i}^{I P}\right)$ and $w\left(2 q_{i}^{G B}\right)$. When $a$ is high enough, the higher quantity under GB will overcome the lower wholesale price, yielding a higher revenue under GB. If a higher revenue is preferable for the manufacturer, GB can create win-win for all the players. Numerical analysis confirms that this result holds for general steepness $e$ not close to 1 , as shown in Figure 4.

In practice, we often observe co-ops or buying groups of similar-size stores (e.g., Ace Hardware). While this can be explained by their common background and interests, our analysis provides further

Figure 4 Manufacturer's Revenue Comparison (Symmetric Retailers) ( $A=1, c=0.1, d=0.01, \theta=0.1$ )

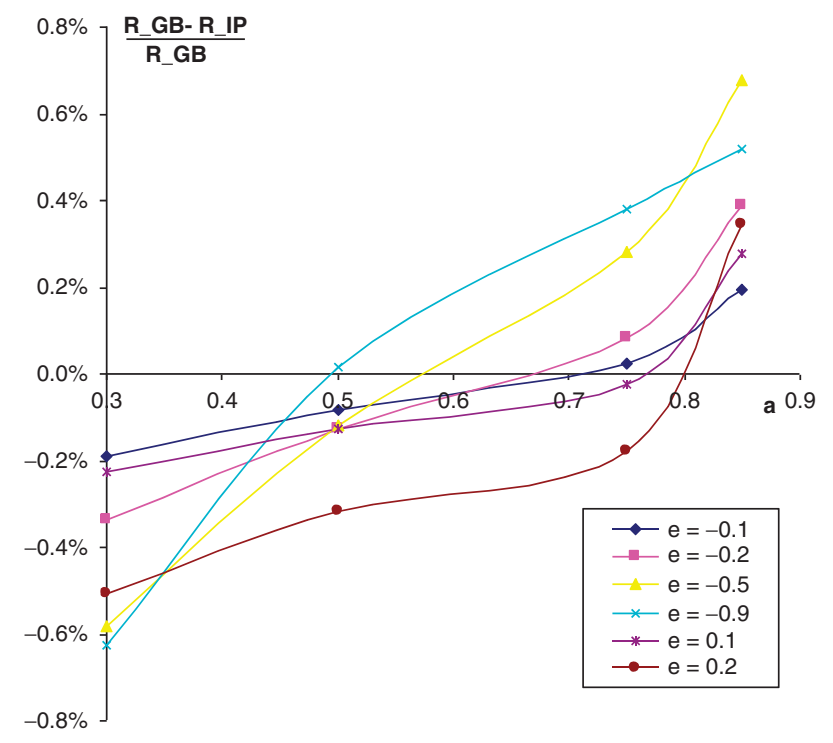

support for such cooperation even in the presence of competition. Some buying groups, e.g., FurnitureFirst, have requirements on the geographical location to prevent members from competing with each other (Heist 2008). The cleaning supplies buying group, DPA, typically has one distributor in a given market. On the other hand, buying group AFFLINK reasons that competition can be a benefit (Mollenkamp 2005). Proposition 3 shows that for symmetric retailers competition may not be a concern if they want to cooperate in buying. Moreover, under certain conditions, the more intense the competition, the higher the profit under GB as suggested in Proposition 1.

\subsection{Asymmetric Market Base}

In the previous section, we show that GB helps soften the competition between symmetric retailers. In practice, group members can also differ from each other. The industrial supplies buying group IDC include some members as small as US $\$ 2$ million a year and a few as large as over US $\$ 50$ million a year. FurnitureFirst, a major US furniture buying group, has members ranging from US\$2 million up to US $\$ 30$ million annually. In 2002, the French supermarket group Intermarche, with sales totaling 37.2 billion Euros, joined forces with its competitor, Spanish Eroski, whose sales were much lower at 4.6 billion Euros (Eurofood 2002). In this section, we examine retailers' difference in their access to customers while assuming they are equally efficient (i.e., $A_{i} \neq A_{j}, c_{i}=c_{j}$ ). Without loss of generality, we consider positive $\Delta A$ only. That is, retailer 1 has a larger market base than retailer 2 . We first study whether retailers' asymmetry level affects the total quantity and the manufacturer's revenue.

Proposition 4. When retailers are asymmetric in market base,

(a) under IP the total quantity $\left(Q^{I P}\right)$ and the manufacturer's revenue $\left(R^{I P}\right)$ are nonincreasing in $\Delta A$.

(b) under $G B$, the total quantity $\left(Q^{G B}\right)$ and the manufacturer's revenue $\left(R^{G B}\right)$ remain constant with $\Delta A$, whereas $\Delta q^{G B}=q_{1}^{G B}-q_{2}^{G B}$ is proportional to $\Delta A$. The total quantity $\left(Q^{G B}\right)$ will increase with competition level $\theta$ and decrease with discount scale $d$.

(c) the manufacturer's revenue under GB can be higher or lower than that under IP.

For IP, the total quantity $Q^{I P}$ decreases or remains constant (e.g., under linear quantity discounts and two-part tariffs) with the asymmetry level $\Delta A$, while the manufacturer's revenue $R^{I P}$ generally decreases with $\Delta A$. Thus, if a higher quantity and revenue are desirable, the manufacturer would prefer symmetric to asymmetric retailers. 
By contrast, under group purchase the total quantity $Q^{G B}$ and the manufacturer's revenue $R^{G B}$ do not depend on $\Delta A$. That is, the manufacturer is indifferent whether retailers are alike or different when they cooperate in purchasing. The difference in retailers' quantity, $\Delta q^{G B}$, is proportional to retailers' level of asymmetry. Intuitively, retailers buy more under intense competition (higher $\theta$ ), whereas a higher discount scale $d$ leads to a higher wholesale price, and thus lower quantity. Consistent with Proposition 3 , the manufacturer's revenue is not always lower under GB for asymmetric retailers.

As the model is not tractable for general steepness $e$, we will first present the analytical results for two special cases: linear quantity discounts $(e=-1)$ and twopart tariffs $(e=1)$, and explore the system behavior under general steepness using a numerical approach.

4.2.1. Linear Quantity Discounts $(e=-1)$. When $e=-1$, the unit wholesale price is $w(q)=a+d q$, with $d<0$. The equilibrium solutions under linear discount schedules are given in Tables 1 and 2. The conditions on the parameters that ensure nonnegativity of all variables are described in (30)-(34) in the supporting information Appendix S1. Note that when the asymmetry level is too high, the small retailer may not make any positive profit. Define $\overline{\Delta A}=(A-c-a)$ $\frac{(1+2 \theta) X+1}{X+1}$ as the largest gap in market base under which retailer 2 remains alive, and we will consider $\Delta A \leq$ $\overline{\Delta A}$ only. We first compare the price, quantity, and profit of the two different retailers.

PROPOSITION 5. When retailers are asymmetric in market base and discount is of linear format, under IP retailer 1 (with a larger market base) may or may not set a higher retail price than retailer 2, although his quantity and profit are always higher than retailer 2. Under GB the retail price, quantity, and profit for retailer 1 are always higher than retailer 2 .

Under IP, retailer 1 naturally enjoys a competitive advantage from its larger market base with a higher quantity and profit, and the retail price is in general higher than that of retailer 2. However, when $d \leq-1 /[2(1+\theta)]$, or equivalently, $|d| \geq 1 /[2(1+\theta)]$, the deep discount from the manufacturer will motivate retailer 1 to set a lower price than retailer 2 . This result differs from Tsay and Agrawal (2000), in which an asymmetry in market base always leads a higher retail price by the larger retailer. This is because the unit wholesale price is fixed in Tsay and Agrawal (2000), rather than decreasing in quantity as in our study. Interestingly, GB removes this incentive so that retailer 1 always charges a higher price than retailer 2 .
Our next comparison shows that the small retailer will always prefer group purchasing, while the big retailer might get hurt from such cooperation.

PROPOSITION 6. When retailers are asymmetric in market base and discount is of linear format, the total quantity under IP does not depend on $\triangle A$, and it is always below that under $G B\left(Q^{G B-l}>Q^{I P-l}\right)$. GB leads to lower price, higher quantity, and higher profit for retailer 2 (with smaller market base) than IP. However, retailer 1 (with larger market base) may not always prefer GB. Specifically,

(a) when $d \geq-\frac{4 \theta^{3}+12 \theta^{2}+6 \theta}{8 \theta^{3}+20 \theta^{2}+12 \theta+2^{2}}$, there exists $\Delta A_{q} \leq \overline{\Delta A}$ such that for $\Delta A \geq \Delta A_{q}$, retailer 1 's quantity is higher under IP;

(b) when $d \geq-\frac{\theta}{1+2 \theta}$, there exists $\Delta A_{p} \leq \overline{\Delta A}$ such that for $\Delta A \geq \Delta A_{p}$, retailer 1 's price is lower under IP;

(c) when $k(\theta, d) \leq 0$, there exists $\Delta A_{\Pi} \leq \overline{\Delta A}$ such that for $\Delta A \geq \Delta A_{\Pi}$, retailer 1's profit is higher under IP, where

$k(\theta, d)$

$$
\begin{aligned}
= & +\left[\frac{\left(\frac{1}{1+\theta}+2 d+\frac{1}{1+2 \theta}\right) \sqrt{\frac{1+d}{1+\theta}}-\left(\frac{1+d}{1+\theta}+\frac{1}{1+2 \theta}\right) \sqrt{\frac{1}{1+\theta}+d}}{\left(\frac{1}{1+\theta}+2 d+1\right) \sqrt{\frac{1+d}{1+\theta}}-\left(\frac{1+d}{1+\theta}+2 d+1\right) \sqrt{\frac{1}{1+\theta}+d}}\right] \\
& \times\left[\frac{\frac{1+d}{1+\theta}+2 d+1}{\frac{1+d}{1+\theta}+\frac{1}{1+2 \theta}}\right] .
\end{aligned}
$$

Moreover, $\Delta A_{q} \leq \Delta A_{p}, \Delta A_{q} \leq \Delta A_{\Pi}$. That is, if retailer 1 's profit (price) is higher (lower) under IP, then its quantity is higher under IP.

Proposition 6 suggests that the discount scale, competition intensity, and asymmetry level jointly affect retailers' GB decisions. Basically, GB is favorable for both retailers when $k(\theta, d) \geq 0$. When $k(\theta, d) \leq 0$, the asymmetry between the retailers plays an important role. Specifically, GB is always preferable when the retailers are similar, which is consistent with Proposition 3. If the two retailers are not alike (i.e., $\Delta A \geq \Delta A_{\Pi}$ ), GB will hurt retailer 1 .

Although it is not possible to solve $k(\theta, d)=0$ by explicitly expressing $d$ as a function of $\theta$ (or vice versa), we characterize the region numerically. As shown in Figure 5, the duopoly model is feasible when $d$ and $\theta$ are below the solid curve (above which the equilibrium solution is invalid with negative quantities or profits). ${ }^{4}$ The feasible region is then divided by the dashed curve $k(\theta, d)=0$ into two: Region I where GB is always advantageous, and Region II where GB is preferable when asymmetry level is below the threshold $\left(\Delta A \leq \Delta A_{\Pi}\right)$. Intuitively, GB is preferable for any value of $d$ when $\theta=0$. When competition is intense (e.g., $\theta \geq 2$ ), the dashed curve 
Figure 5 Group Buying and Individual Purchase Region (Linear Quantity Discounts)

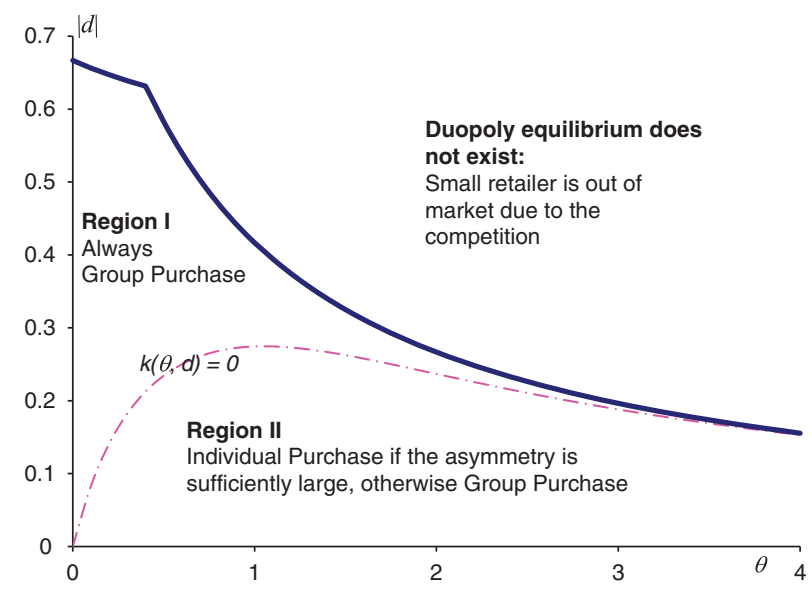

$k(\theta, d)=0$ is approaching the solid curve, so that the asymmetry level becomes critical to the GB decision. When competition is mild (e.g., $\theta \leq 2$ ), the cooperation effect will dominate the competition effect under deep discount (e.g., $|d| \geq 0.28$ ) and GB is preferable. Otherwise for flat discounts (low $|d|$ ), again the asymmetry level determines whether retailers will cooperate.

Recall that for the general QDF, the total quantity and the manufacturer's revenue under GB do not depend on $\Delta A$, as shown in Proposition 4. For linear discount schedules, the total quantity under IP is also independent of $\Delta A$, whereas the revenue under IP decreases with the level of asymmetry. Similar to the symmetric case, the revenue comparison depends on the base price $a$ as follows (see proof of Proposition 4(c) in the supporting information Appendix S1 for details):

(a) if $a \geq a_{0}$, GB leads to higher revenue for symmetric retailers and $R^{G B_{-} l} \geq R^{I P \_l}$ for $\Delta A \leq \overline{\Delta A}$;

(b) if $a_{1} \leq a<a_{0}$, there exists a unique value $\Delta A_{0} \leq \overline{\Delta A}$, where $R^{G B \_l} \geq R^{I P-l}$ for $\Delta A \geq \Delta A_{0}$;

(c) if $a<a_{1}$, revenue under IP decreases but remains higher than that under $G B$, and $R^{G B} l^{l}<R^{I P \_l}$ for $\Delta A \leq \overline{\Delta A}$.

We next present the analytical result under the special case of two-part tariffs.

4.2.2. Two-Part Tariffs $(e=1)$. Under a two-part tariff, the unit wholesale price is given by $w(q)=a+d / q$ with $d>0$. Two-part tariffs are commonly used in practice due to their simple structure (see Tirole 1988 and the discussion therein), and have been well studied in the literature (e.g., Dolan 1987, Ingene and Parry 1995, Raju and Zhang 2005). If each retailer is required to pay the manufacturer a constant unit price plus a fixed fee for shipping and handling (e.g., transportation), this price schedule would simply be a two-part tariff.

The total cost under a two-part tariff is $T C(q)=$ $a q+d$ for $q>0$ and $T C(0)=0$. By (6) and (10), retailer $i$ 's profit under IP and GB can be written as

$$
\begin{gathered}
\Pi_{i}^{I P \_t}=\frac{\left(q_{i}^{I P \_t}\right)^{2}}{1+\theta}-d, \text { and } \\
\Pi_{i}^{G B \_t}=\frac{\left(q_{i}^{G B \_t}\right)^{2}}{1+\theta}-\frac{d}{1+\theta}\left(\frac{q_{i}^{G B \_t}}{Q^{G B \_t}}\right)^{2},
\end{gathered}
$$

respectively. In the initial equilibrium, both retailers make nonnegative profits by individually purchasing from the manufacturer. They now consider the option of cooperation in buying. The equilibrium IP and GB solutions for two-part tariffs are given in Tables 1 and 2. The conditions that ensure a sensible model are given in (36)-(38) in the supporting information Appendix S1. The comparisons between the retailers and the impact of discount scale and competition intensity are summarized below.

PROPOSITION 7. When retailers are asymmetric in market base and the discount is a two-part tariff,

(a) retailer 1 (with larger market base) will set a higher price, and enjoy a higher retail quantity and profit under either IP or GB compared to retailer 2;

(b) under IP retail price and quantity do not depend on $d$, while retail profit is linearly decreasing in $d$. Also more intense competition leads to higher retail quantity for both retailers and lower retail price for retailer 1 under IP.

Under IP, the marginal cost remains constant at $a$ after the fixed fee $d$ is incurred, although a two-part tariff, de facto, corresponds to a quantity discount with decreasing unit wholesale price. Thus, the fixed fee $d$ behaves as a sunk cost and will not affect each retailer's pricing or quantity decision. Note that $d$ cannot be too high for both retailers to have positive profits (e.g., $d \leq(1+\theta)\left(\frac{A-c-a}{2+\theta}\right)^{2}$ by condition (37) in Appendix S1). We now compare IP and GB under two-part tariffs.

PROPOSITION 8. When retailers are asymmetric in market base and the discount is a two-part tariff,

(a) GB leads to higher retail price and lower retail quantity for both retailers;

(b) both retailers are better off under GB. The profit advantage of group purchase is monotonically decreasing for the large retailer $\left(\partial\left(\Pi_{1}^{G B}-\Pi_{1}^{I P}\right) /\right.$ $\partial \Delta A \leq 0)$ and monotonically increasing for the small retailer $\left(\partial\left(\Pi_{2}^{G B}-\Pi_{2}^{I P}\right) / \partial \Delta A \geq 0\right)$;

(c) the manufacturer's total quantity and revenue are higher under IP than under GB. 
Table 4 Comparison between IP and GB (Asymmetric Retailers)

\begin{tabular}{|c|c|c|c|}
\hline & \multicolumn{2}{|c|}{ Linear schedule $(e=-1)$} & \multirow{2}{*}{$\frac{\text { Two-part tariff }(e=1)}{\text { Retailer } i, i=1,2}$} \\
\hline & Retailer 1 (larger market base) & Retailer 2 & \\
\hline Retailer price & $p_{1}^{G B_{-} I} \lessgtr p_{1}^{\mid P_{-} I}$ depending on $d, \theta, \Delta A$ & $p_{2}^{G B \_I} \leq p_{2}^{\mid P \_I}$ & $p_{i}^{G B_{-} t} \geq p_{i}^{I P_{-} t}$ \\
\hline Retailer quantity & $q_{1}^{G B_{-} I} \lessgtr q_{1}^{\mid P_{-} I}$ depending on $d, \theta, \Delta A$ & $q_{2}^{G B_{-} I} \geq q_{2}^{\mid P_{-} I}$ & $q_{i}^{G B_{-} t} \leq q_{i}^{I P_{-} t}$ \\
\hline Retailer profit & $\Pi_{1}^{G B_{-} I} \lessgtr \Pi_{1}^{I P_{-} I}$ depending on $d, \theta, \Delta A$ & $\Pi_{2}^{G B_{-} I} \geq \pi_{2}^{\mid P_{-} I}$ & $\Pi_{i}^{G B_{-} t} \geq \Pi_{i}^{I P_{-} t}$ \\
\hline Total quantity & $Q^{G B_{-} I} \geq Q^{\mid P_{-} I}$ & & $Q^{G B_{-} t} \leq Q^{I P_{-} t}$ \\
\hline Manufacturer revenue & $R^{G B_{-} I} \lesseqgtr R^{\mid P_{-} I}$ & & $R^{G B_{-} t} \leq R^{I P_{-} t}$ \\
\hline
\end{tabular}

Conventional wisdom suggests that when buyers purchase together, they are likely to acquire a higher quantity at a lower unit wholesale price. However under two-part tariffs, buyers will actually buy less under group purchase, regardless of the presence of competition. As discussed before, under IP the fixed fee $d$ does not affect each retailer's quantity decision. Under GB, retailer $i$ 's payment to the manufacturer is

$$
a q_{i}^{G B \_t}+\frac{q_{i}^{G B \_t}}{Q^{G B \_t}} d
$$

That is, the fixed fee $d$ is shared by retailers based on the ratio $q_{i}^{G B_{-} t} / Q^{G B_{-} t}$. This serves as an incentive for each retailer to scale back and buy less under GB.

The profit comparison suggests that if the two competing retailers currently purchase individually under a two-part tariff, they will be better off by switching to GB regardless of their asymmetry level or competition intensity. Moreover, their cooperation will always lead to a lower revenue for the manufacturer. These results are not surprising given the special structure of two-part tariffs. Table 4 summarizes the comparison between IP and GB for both linear schedules and two-part tariffs.

4.2.3. General Steepness $e$. As the results for the two special cases differ, it would be interesting to investigate the system of asymmetric retailers under general steepness of $e$. Not surprisingly, for $e$ close to -1 prices and quantities behave similarly as under linear schedules, whereas for $e$ close to 1 they behave similarly as under two-part tariffs. In this section, we focus on the comparison of retailer profits and manufacturer's revenue between IP and GB. In all the numerical studies, we restrict to the parameter range that ensures a sensible model with positive prices, quantities, and profits.

4.2.3.1. Retailer's profit: GB Vs. IP. We have shown that, under linear discount schedules, it is possible to have the big retailer not willing to cooperate, whereas the small player always benefits from GB. On the other hand, under two-part tariffs both retailers prefer group purchase. Numerical investigation shows that for $e \in[-1,1]$, the results obtained under linear discounts are quite robust. As long as the steepness $e$ is not close to 1 , in a competitive and sufficiently asymmetric environment, GB can be detrimental for the retailer with a larger market base, whereas the smaller retailer always benefits from GB. Figure 6 depicts retailer 1's relative profit difference under GB and IP, $\left(\Pi_{1}^{G B}-\Pi_{1}^{I P}\right) / \Pi_{1}^{I P}$ for $e= \pm 0.1, \pm 0.2, \pm 0.5$, and -0.9 . Retailer 1 's profit difference for $e=0.9$ is always positive and thus is omitted.

Under GB, retailer 1's competitive advantage from its larger market base is weakened because now both retailers have the same unit wholesale price. On the other hand, the extra demand from retailer 2 helps retailer 1 obtain a better discount from the manufacturer. When the benefit from demand aggregation is sufficient to cover its loss in competitive advantage (e.g., when asymmetry level is low), retailer 1 will join group purchase. Otherwise if retailer 2 becomes much more competitive through GB, retailer 1 will receive a lower profit, and naturally, choose not to group buy. As a result, while the small retailer is

Figure 6 Profit Comparison for Retailer 1 (Large Market Base) $(A=1$, $\mathrm{C}=0.3, a=0.3, \theta=3, d=-0.1$ for $e<0, d=0.01$ for $e>0$ )

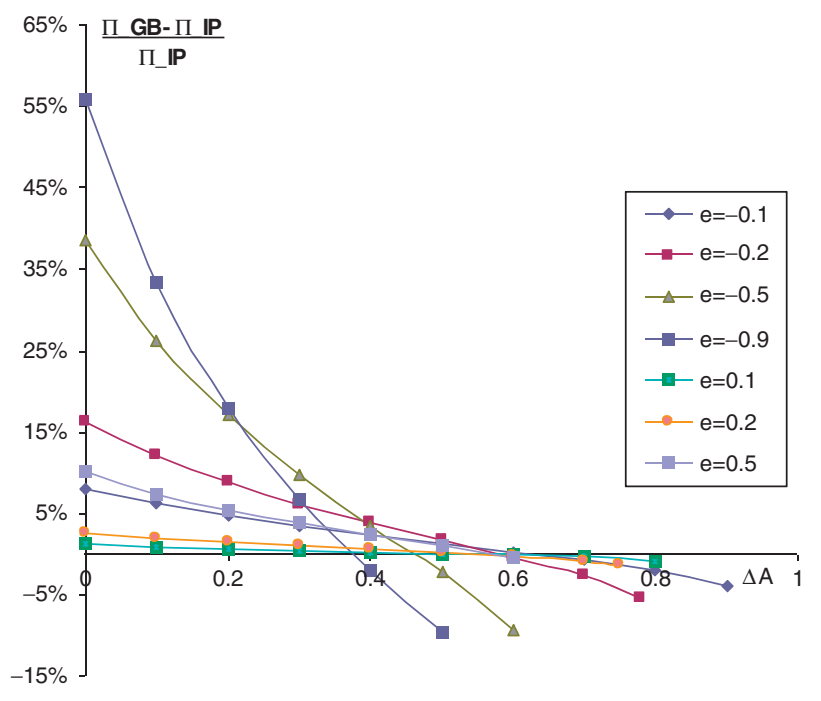


always interested in forming a group with the large retailer, such cooperation may never materialize.

Discussions from online GB forums show that people have very different opinions regarding local buying groups. While some agree that such cooperation is more manageable because logistics are easier and there are no trust problems, others believe that cooperation among local members will not be advantageous because they are competing in the same market. This study shows that both concerns are valid, and a careful evaluation is needed for the large retailer.

Our results add a caveat to the general belief that GB always benefits buyers. Some buying groups consist of local retailers who might compete with each other. For example, Stagbuyinggroup.com, a company that specializes in sport, outdoor, and leisure sectors, has over 400 independent retailers all over the United Kingdom, with some outlets in proximity to each other. Before engaging in any purchasing cooperation, retailers should be aware of the possible outcomes depending on the competition and their differences.

4.2.3.2. Manufacturer's revenue: GB vs. IP. We have shown that under linear schedules, manufacturer's revenue can be higher under GB if the base price $a$ is sufficiently high, whereas under two-part tariffs, revenue is always lower under GB. Numerical investigation suggests that GB can lead to higher revenue for steepness $e$ not close to 1 and sufficiently high asymmetry. When $e$ is close to $1, \mathrm{~GB}$ always results in a lower revenue.

\subsection{Asymmetric Efficiency}

We now study another form of asymmetry created by the efficiency gap between the two retailers $(\Delta c \neq 0)$ while assuming $\Delta A=0$. Without loss of generality, we consider positive $\Delta c$ only, i.e., retailer 2 is more efficient. For comparisons between IP and GB, the results do not differ qualitatively from those under market base asymmetry. Hence, we briefly comment on the insights specific for the case of asymmetric efficiency (the solutions are available from the authors).

For two-part tariffs, the comparisons are similar to Propositions 7-8. For linear discounts, we find that retailer 2 will always set a lower price, have higher quantity and higher profit than (the less efficient) retailer 1, under both GB and IP. This result slightly differs from that under asymmetric market base. Parallel to the case of asymmetric market base, the conditions identified in Proposition 6 will lead to cutoff points $\Delta c_{p}, \Delta c_{q}$, and $\Delta c_{\Pi}$ such that the price, quantity, and profit are higher in IP for the more efficient retailer 2 when $\Delta c$ is beyond the cutoff points, respectively. Concerning the manufacturer, we have a similar conclusion as in Proposition 4. For general steepness, numerical investigation confirms that retailer 1 will always prefer GB, while retailer 2 may not always cooperate when efficiency gap $\Delta c$ is large and discount level $|d|$ is low.

\subsection{Asymmetry in Both Market Base and Efficiency}

We have shown that either dimension of asymmetry has a similar impact on retailers' GB decisions. For the general case where firms differ in both dimensions, there are two possible cases: (1) $\Delta A \Delta c<0$, i.e., the retailer with a larger market base also has a lower unit operating cost; and (2) $\Delta A \Delta c>0$, i.e., the retailer with a small market base is more efficient. Usually a high market base is correlated with low operating costs due to economies of scale. Nevertheless we sometimes do observe small retailers who excel in operational efficiency.

For case (1), all the results obtained for asymmetry in one dimension still hold. In fact, when $\Delta A \Delta c<0$, the asymmetry between retailers is strengthened in the sense that the "strong" retailer becomes even stronger. For case (2), results depend on which asymmetry dominates. In particular, if $\Delta A \geq \Delta c(1+2 \theta)$, the asymmetry in market base outweighs the amplified gap in operational efficiency, and the retailer with a larger market base is the "strong" one. Otherwise if $\Delta A<\Delta c(1+2 \theta)$, the efficient retailer is the strong player. Similar as before, the weak retailer will always prefer $\mathrm{GB}$, while the strong one may or may not cooperate. Note that the asymmetry in operational efficiency $(\Delta c)$ is reinforced by competition through the multiplier $1+2 \theta$. For the special case $\theta=\frac{\Delta A-\Delta c}{2 \Delta c}$, the two asymmetries will cancel out, and these two retailers are virtually symmetric. This implies that when each retailer is good at one dimension but not both, GB is more likely to materialize. This is an interesting result, which suggests that retailers of different strengths are more likely to cooperate.

\section{Extension}

\subsection{Nonlinear Demand Functions}

In many competitive equilibrium analyses, linear demand functions are often used because of their tractability in providing analytical results. Yet we expect demand nonlinearity in many real problems. In the investigation below, we supplement the preceding discussion by analyzing three nonlinear demand functions commonly used in the literature (Choi 1991, Kadiyali et al. 2000, Lee and Staelin 1997, Moorthy 1988, Vives 1999)
(a) $q_{i}=A_{i} p_{i}^{-m} p_{j}^{n}, A_{i} \geq 0, m>1,0 \leq n \leq m$,
(b) $q_{i}=e^{A_{i}-m p_{i}+n p_{j}}, A_{i} \geq 0,0 \leq n \leq m$, and
(c) $q_{i}=A_{i}-m \ln p_{i}+n \ln p_{j}, A_{i} \geq 0,0 \leq n \leq m$. 
$n$ is a substitutability parameter; when it is zero, each retailer's demand is independent of the other retailer's price. $m \geq n \geq 0$ is required to ensure that retailer $i^{\prime}$ s demand is more sensitive to its own price than to the competitor's and the total demand does not increase when both retail prices increase. (a) is known as the constant elasticity demand function, where $m$ and $n$ are retailer $i$ 's demand elasticities to its own price and to the competitor's price, respectively. In the absence of quantity discounts and group purchase, this class of functions is known to result in price strategies that are independent of the competitor's strategy (Choi 1991, Moorthy 1988). Such property no longer holds under general quantity discounts. (b) and (c), referred to as semi-log demand functions, are commonly used in empirical studies, where (b) is sometimes called exponential demand function (Lee and Staelin 1997).

Owing to the functional complexity, analytical solutions are elusive for these nonlinear demand functions. For each demand function, we derive the first-order conditions under IP and GB, based on which we find the equilibrium numerically. We experiment with a wide range of parameters by normalizing $A$ to 1 and $c$ to 0.1 , and varying $a$ between 0.2 and $0.8, e$ between -1 and 1 , and $d$ across feasible values. All of the numerical studies are carried within the range that ensures individual rationality and nonnegativity. Our analysis suggests that results obtained under the linear demand function (1) are robust. Specifically, cooperation may not materialize in presence of sufficient asymmetry because the stronger retailer can get hurt from joint purchasing. Also, the manufacturer's revenue can be higher under GB.

One result that differs concerns the constant elasticity demand. Proposition 3 shows that symmetric retailers always prefer group purchase under the linear demand function, a result that also holds for (b) and (c). However for (a), symmetric retailers may get hurt from cooperation when $m$ is low, $n$ is medium, and steepness $e$ is not close to 1 (e.g., $e<0.3$ ).

To understand this result, note that, in general, demand elasticity increases with price (e.g., linear and semi-log demand functions). That is, consumers become more price sensitive when the product becomes more expensive. However, under constant elasticity demand, especially when elasticity $m$ is low, a significant change in price may not alter demand as much. As $n$ varies from 0 to $m$, a more intense competition leads to lower retail price and higher quantity. When competition is fairly weak (i.e., $n \approx 0$ ), the cooperation effect dominates and GB is preferable. When competition becomes mild for medium values of $n$, IP is preferable because the low demand elasticity $m$ allows each retailer to charge a much higher price under IP than under GB, at almost no risk in losing demand. When competition is intense (e.g., $n \approx m$ ), GB is again advantageous because it helps soften the competition.

Note that GB is again preferable for symmetric retailers under higher values of $m$, where the higher demand elasticity depresses the retail price under IP, and GB will again be preferable regardless of the competition level. Overall our numerical analysis suggests that results obtained under the linear demand function are robust, except for the constant elastic demand with low demand elasticity and mild competition. For parameters in this range, retailers might continue to be worse off under GB when they become slightly different, so that even the weak player may prefer IP.

\subsection{Three or More Competing Retailers}

In the investigation of how competition affects retailers' cooperation decision, we follow the literature (e.g., Ingene and Parry 1995, Tsay and Agrawal 2000) by considering duopoly with two retailers. In reality, some groups consist of multiple retailers who vary in size. For example, members of NetPlus include some distributors with sales at US\$50 million, two with sales in US $\$ 40$ million and a half dozen or so with sales more than US\$20 million. In this section, we focus on market base asymmetry and consider the special case of two symmetric small retailers and one big retailer, which sheds light on the analysis of three or more competing retailers.

Let retailers 1 and 2 be the two symmetric retailers with the same market base, and retailer 3 be the big retailer $\left(A_{1}=A_{2} \leq A_{3}\right)$. Similar as before, we obtain retailer $i$ 's demand function from Shapley and Shubik (1969) as

$$
q_{i}=A_{i}-p_{i}+\theta\left(\frac{1}{n} \sum_{j=1}^{n} p_{j}-p_{i}\right), \quad \theta \geq 0 .
$$

Define $\Delta A=\frac{1}{3}\left(A_{3}-A_{1}\right)$ so that $A=\frac{1}{3}\left(A_{1}+A_{2}+\right.$ $\left.A_{3}\right), A_{1}=A_{2}=A-\Delta A, A_{3}=A+2 \Delta A$. Again, $\Delta A$ measures the level of asymmetry between the big retailer and the small retailers. The analysis is similar to the duopoly case, and is omitted here. We explore the coalition formation for general steepness numerically, and report one representative example in Table 5. Our major findings are as follows:

1. If the asymmetry level is high, the big retailer will not cooperate with either small retailer, a result consistent with Proposition 6. In this case, the two small retailers will group buy. This possibly explains that in 2003, Mexico's three largest retailers, Grupo Gigante, Organization Soriana, and Comercial Mexicana, joined forces in a buying and operations alliance in order to compete against the Wal-Mart-owned Walmex. Also, 
Table 5 Profit Comparison for Three Retailers*

\begin{tabular}{|c|c|c|c|c|c|c|c|c|c|}
\hline \multirow[b]{2}{*}{$\Delta A$} & \multicolumn{5}{|c|}{ Retailer 1 profit (small retailer) } & \multicolumn{4}{|c|}{ Retailer 3 profit (large retailer) } \\
\hline & $\mathrm{GB}(1,2,3)$ & $\mathrm{GB}(1,2)$ & $\mathrm{GB}(1,3)$ & IP & $\mathrm{GB}(2,3)$ & $\mathrm{GB}(1,2,3)$ & $\mathrm{GB}(1,2)$ & $\mathrm{GB}(1,3)$ & IP \\
\hline 0 & 0.07835 & 0.07775 & 0.07775 & 0.07670 & 0.07653 & 0.07835 & 0.07653 & 0.07775 & 0.07670 \\
\hline 0.1 & 0.06313 & 0.06239 & 0.06269 & 0.06150 & 0.06135 & 0.11370 & 0.11192 & 0.11313 & 0.11210 \\
\hline 0.2 & 0.04955 & 0.04872 & 0.04925 & 0.04798 & 0.04783 & 0.15563 & 0.15398 & 0.15512 & 0.15419 \\
\hline 0.3 & 0.03762 & 0.03674 & 0.03743 & 0.03614 & 0.03599 & 0.20412 & 0.20273 & 0.20373 & 0.20295 \\
\hline 0.4 & 0.02733 & 0.02643 & 0.02723 & 0.02596 & 0.02582 & 0.25918 & 0.25816 & 0.25895 & 0.25839 \\
\hline 0.5 & 0.01868 & 0.01781 & 0.01865 & 0.01747 & 0.01733 & 0.32080 & 0.32027 & 0.32080 & 0.32050 \\
\hline 0.6 & 0.01167 & 0.01088 & 0.01169 & 0.01064 & 0.01052 & 0.38899 & 0.38909 & 0.38927 & 0.38931 \\
\hline 0.7 & 0.00630 & 0.00564 & 0.00635 & 0.00549 & 0.00539 & 0.46374 & 0.46462 & 0.46438 & 0.46483 \\
\hline 0.8 & 0.00257 & 0.00210 & 0.00263 & 0.00203 & 0.00195 & 0.54507 & 0.54693 & 0.54615 & 0.54711 \\
\hline 0.9 & 0.00049 & 0.00026 & 0.00053 & 0.00025 & 0.00022 & 0.63295 & 0.63616 & 0.63466 & 0.63627 \\
\hline
\end{tabular}

*Group binding (GB) $(1,2,3)$ means all three retailers group purchase. GB $(1,2)$ means only the two small retailers group purchase. GB $(1,3)$ means only retailer 1 and retailer 3 group purchase, while leaving retailer 2 alone. IP means all three retailers individual purchase. GB $(2,3)$ means retailer 2 and 3 group purchase, while leaving retailer 1 alone.

$(A=1 ; c=0.1 ; a=0.3 ; d=-0.01 ; \theta=2 ; e=-0.5)$.

large grocery buying groups in France typically refuse members with too low a turnover, while small retailers sometimes form their own groups (Dobson Consulting 1999).

2. For medium or low asymmetry levels, for a wide range of parameters, all three players would form one group. However, sometimes the big retailer will be interested in cooperating with one, but not both small retailers. Basically after the big retailer and one small retailer form a subcoalition, they might find it unattractive to further include the third player. To some extent, the formation of the subcoalition enlarges the asymmetry gap so that no further cooperation takes place.

Our limited analysis shows that ultimately competition together with asymmetry drives the decision of whether to group purchase. However, the general problem of three or more competing retailers can be quite complex because players can form subcoalitions that enlarge or shrink the asymmetry gap. The full investigation of this problem, although beyond the scope of this paper, is a promising direction for future research.

\section{Discussion and Conclusion}

Although GB has been widely used in a variety of markets and contexts, there is a lack of decision analysis for firms who are involved. In this paper, we construct a general model of competing retailers with two possible strategies: IP or GB, given a quantity discount schedule from the manufacturer. Based on linear demand curves, we offer a number of insights on retailers' GB decisions. Intuitively, GB is always advantageous in the absence of competition. Under competition, symmetric retailers are always better off under GB. Interestingly, when discount is deep and competition is mild, symmetric retailers might prefer more intense competition when they cooperate. On the other hand, a deeper discount is not always beneficial to retailers under IP.

When retailers are asymmetric (i.e., differ in market base or operational efficiency), GB clearly helps the "weak" player (e.g., the retailer with smaller market base or higher operational cost), while the "strong" player may or may not prefer cooperation, depending on the competition level, the discount schedule, and the level of asymmetry. In fact, GB in general weakens the competitive advantage of the strong player, who at the same time enjoys a lower wholesale price that becomes available because of its rival's demand. Especially when the asymmetry gap is large, the loss in competitive advantage will outweigh the gain from joint purchasing so that GB may not materialize. Interestingly, GB is more likely to form between retailers who are competitive in different, but not all dimensions. Our investigation with nonlinear demand curves suggests that results obtained under linear demand curves are robust, except for some minor differences under the constant elasticity demand with low elasticity.

Our results are based on several assumptions. First, we assume that the quantity discount schedule is exogenously given, which is reasonable under the Robinson-Patman Act. However, sometimes the quantities of buying groups are beyond the price menu specified by the manufacturer, and they need to negotiate the price with the seller. In the current study, we examine the retailers' perspective and only 
consider the manufacturer's revenue. An opportunity to build upon this work is to consider the manufacturer's optimal strategy when retailers purchase together.

Secondly, we have shown that under the commonly used uniform allocation rule, the retailers pay the same unit price in group purchase and the strong retailer may not want to participate. In this case, there might exist other allocation rules that enable the cooperation and result in a win-win outcome. In practice, buying groups operate on egalitarian principles, whereas others arrange better deals for large members because they contribute more to the aggregate purchase (Lindsay 2009). The majority literature on cost-sharing mechanisms has focused on the normative properties (e.g., fairness), without considering competition (Hougaard and Thorlund-Petersen 2000, Moulin 1996). One important direction is to examine alternative allocation schemes when buyers compete.

Our paper makes the intuitive assumption that the total cost increases with purchasing quantity. Thus, it is never advantageous for retailers to hold back any inventory (i.e., purchase more than they can sell). However, discount schedules in practice often include discrete breakpoints, under which the total cost might remain the same or even fall if more units are purchased over certain ranges. The area of the price schedule where this occurs is called a "window" (Wilcox et al. 1987), and its existence can be explained by the easiness in describing discrete discounts in practice (Carlton and Waldmann 2008). Prior literature has studied buyers' ordering decision in the presence of such opportunities (e.g., Arcelus and Rowcroft 1992, Sethi 1984). Future research can examine whether holding back would affect the economics of GB.

This is the first paper that studies GB in a channel context. Another relevant question is whether the intensity of rivalry at the retail stage has any implications for the total surplus available between the two levels. For example, for German grocery buying groups, the intense competition between members appears in turn to lead to greater pressure on sellers to accept lower margins, while the negotiations between buying groups and sellers are more relaxed in the United Kingdom (Dobson Consulting 1999). By considering the manufacturer as an active member, future study could examine channel coordination under GB.

In this paper, we have not considered other valueadded services (advertising, logistics, etc.) that are usually part of the benefits of a buying group, which can be incorporated in future studies. Our equilibrium analysis relies on the assumption of common knowledge of all model parameters. Especially, the information on rival's market base and operational cost is needed for retailers to choose their strategies. An important direction is to examine firms' GB decision under incomplete information.

\section{Acknowledgments}

The authors would like to thank the editors, the area editor, and the two anonymous reviewers for their valuable and insightful comments, which helped improve the paper significantly.

\section{Notes}

${ }^{1}$ Examples include the well-known grocery chain Independent Grocers Association (or IGA), and Ace Hardware, TruServ, and Do It Best in retail hardware (Dana 2006).

${ }^{2}$ Under certain conditions (e.g., very intense competition), it is possible for one or both retailers to exit the market to avoid negative profits. As we study GB formation in a competitive environment, we restrict to the range of parameters where the duopoly equilibrium exists under both IP and GB. The issue of market exit or entry under GB is beyond the scope of this paper.

${ }^{3}$ Here we follow the standard economic argument that, when supply of a good expands, the price falls (assuming the demand curve is downward sloping) and consumer surplus increases.

${ }^{4}$ This curve is generated by conditions (31), (32), and (34) that ensure nonnegative prices, quantities, and profits for asymmetric retailers.

\section{References}

Anand, K. S., R. Aron. 2003. Group buying on the web: A comparison of price-discovery mechanisms. Manage. Sci. 49(11): 1546-1562.

Anupindi, R., Y. Bassok, E. Zemel. 2001. A general framework for the study of decentralized distribution systems. Manuf. Serv. Oper. Manage. 3(4): 349-368.

Arcelus, F. J., J. E. Rowcroft. 1992. All-units quantity-freight discounts with disposals. Eur. J. Oper. Res. 57(1): 77-88.

Buchanen, J. M. 1953. The theory of monopolistic quantity discounts. Rev. Econ. Stud. 20(3): 199-208.

Carlton, D. W., M. Waldmann. 2008. Safe harbors for quantity discounts and bundling. Discussion paper, Economic Analysis Group of the Antitrust Division.

Chen, F., A. Federgruen, Y.-S. Zheng. 2001. Coordination mechanisms for a distribution system with one supplier and multiple retailers. Manage. Sci. 47(5): 693-708.

Chen, J., X. Chen, X. Song. 2002. Bidder's strategy under groupbuying auction on the internet. IEEE Trans. Syst. Man Cybern. A, Syst. Humans 32(6): 680-690.

Chen, R., C. Li, R. Zhang. 2008. Group-buying mechanisms for business-to-business exchanges. Working paper, University of California at Davis, Davis, CA.

Chen, R., S. Yin. 2008. The equivalence of uniform and Shapley value-based cost allocations in a specific game. Oper. Res. Let. (forthcoming).

Chen, X. 2009. Inventory centralization games with price-dependent demand and quantity discount. Oper. Res. 57(6): 1394-1406. 
Chipty, T. 1995. Horizontal integration for bargaining power: Evidence from the cable television industry. J. Econ. Manage. Strategy 4(2): 375-397.

Choi, C. 1991. Price competition in a channel structure with a common retailer. Mark. Sci. 10(4): 271-296.

Coughlan, A. T., B. Wernerfelt. 1989. On credible delegation by oligopolists: A discussion of distribution channel management. Manage. Sci. 35(2): 226-239.

Crowther, J. 1964. Rationale for quantity discounts. Harv. Bus. Rev. 42(2): 121-127.

Dada, M., K. N. Srikanth. 1987. Pricing policies for quantity discounts. Manage. Sci. 33(10): 1247-1252.

Dana, J. 2006. Buyer groups as strategic commitment. Working paper, Kellogg School of Management, Northwestern University, Evanston, IL.

Dobson Consulting. 1999. Buyer power and its impact on competition in the food retail distribution sector of the European Union. Prepared for the European Commission-DGIV Study.

Dolan, R. 1987. Quantity discounts: Managerial issues and research opportunities. Mark. Sci. 6(1): 1-22.

Erhun, F., P. Keskinocak, S. Tayur. 2008. Dynamic procurement, quantity discounts, and supply chain efficiency. Prod. Oper. Manag. 17(5): 1-8.

Eurofood. 2002. Eroski and Intermarche form European buying group-Food Retailing-Eroski Sociedad Cooperativa-Brief Article. October 10.

Gray, K. 2003. Consortia, buying groups and trend in demand aggregation. The 88th Annual International Supply Management Conference Proceedings, Nashville, TN.

Grocer. 2006. Rivals buy into alliance (alliances and partnerships between Co-operative Group (CWS) Ltd and SPAR (UK) Ltd). August 26.

Hartman, B., M. Dror, M. Shaked. 2000. Cores of inventory centralization games. Games Econ. Behav. 31(1): 26-49.

Heist, L. 2008. Buyer Groups Provide Power in Number for Furniture Retailers. Available at http://www.furniturestyle. com (accessed date September 12, 2009).

Hendrick, T. E. 1997. Purchasing consortiums: Horizontal alliances among firms buying common goods and services What? Who? Why? How? The Center for Advanced Purchasing Studies, Focus Study.

Horn, H., A. Wolinsky. 1988. Bilateral monopolies and incentives for merger. RAND J. Econ. 19(3): 408-419.

Hougaard, J. L., L. Thorlund-Petersen. 2000. The stand-alone test and decreasing serial cost sharing. Econ. Theory 16(2): 355-362.

IGD Retailing Factsheets. 2007. Grocery Buying Groups. Available at http:/ / www.igd.com (accessed date September, 2009).

Inderst, R., C. Wey. 2003. Bargaining, mergers, and technology choice in bilaterally oligopolistic industries. RAND J. Econ. 34(1): 1-19.

Ingene, C. A., M. E. Parry. 1995. Channel coordination when retailers compete. Mark. Sci. 14(4): 360-377.

Ingene, C. A., M. E. Parry. 1998. Manufacturer-optimal wholesale pricing when retailers compete. Mark. Lett. 9(1): 65-77.

Jeuland, A., S. Shugan. 1983. Managing channel profits. Mark. Sci. 2(3): 239-272.

Kadiyali, V., P. Chintagunta, N. Vilcassim. 2000. Manufacturerretailer channel interactions and implications for channel power: An empirical investigation of pricing in a local market. Mark. Sci. 19(2): 127-148.

Katz, M. L. 1989. Vertical contractual relations. Schmalensee, R., R. D. Willig eds Handbook of Industrial Organization. Vol. 1. Elsevier Science Publishers B.V., New York, NY, 655-721.
Kauffman, R. J., B. Wang. 2002. Bid together, buy together: On the efficiency of group-buying business models in internet-based selling. Lowry, P. B. , J. O. Cherrington, R. R. Watson eds Handbook of Electronic Commerce in Business and Society. CRC Press, Boca Raton, FL, 99-137.

Knott, J. 2009. Why smaller dealers join buying groups. CEPro, March.

Kuipers, P. 2005. Italy: Retail modernisation with help from abroad. Elsevier Food Int. 8(3).

Lee, E., R. Staelin. 1997. Vertical strategic interaction: Implications for channel pricing strategy. Mark. Sci. 16(3): 185-207.

Lee, E., R. Staelin. 2000. A general theory of demand in a multiproduct multi-outlet market. Working paper, Fuqua School of Business, Duke University, Durham, NC.

Lindsay, M. A. 2009. Antitrust and group purchasing. Antitrust 23(3): 66-73.

Marvel, H. P., H. Yang. 2008. Group purchasing, nonlinear tariffs and oligopoly. Int. J. Ind. Organ. 26(5): 1090-1105.

McGuire, T. W., R. Staelin. 1983. An industry equilibrium analysis of downstream vertical integration. Mark. Sci. 2(2): 161-191.

Mitchell, P. 2002. Internet-enabled group purchasing: Get a buy with a little help from your friends. Technical Report, AMR Research.

Mollenkamp, B. 2005. Jan/San buying/marketing groups: Group mentality. Sanitary Maintenance, August.

Moorthy, K. S. 1987. Managing channel profits: Comment. Mark. Sci. 6(4): 375-379.

Moorthy, K. S. 1988. Strategic decentralization in channels. Mark. Sci. 7(4): 335-355.

Monahan, J. P. 1984. A quantity discount pricing model to increase vendor profits. Manage. Sci. 30(6): 720-726.

Moulin, H. 1996. Cost sharing under increasing returns: A comparison of simple mechanisms. Games Econ. Behav. 13(2): 225-251.

Oi, W. Y. 1971. A Disneyland dilemma: Two-part tariffs for a Mickey Mouse monopoly. Q. J. Econ. 85(1): 77-96.

Padmanabhan, V., I. P. L. Png. 1997. Manufacturer's returns policies and retail competition. Mark. Sci. 16(1): 81-94.

Raju, J., Z. J. Zhang. 2005. Channel coordination in presence of a dominant retailer. Mark. Sci. 24(2): 254-262.

Rauen, C. 1992. Buying groups deliver discounts. Nation's Business, May.

Rosenblatt, M. J., H. L. Lee. 1985. Improving profitability with quantity discounts under fixed demand. IIE Trans. 17(4): 388-395.

Schotanus, F. 2007. Horizontal cooperative purchasing. Ph.D. dissertation, University of Twente, Enschede.

Schotanus, F., J. Telgen, L. de Boer. 2009. Unraveling quantity discounts. Omega 37(3): 510-521.

Sethi, S. P. 1984. A quantity discount lot size model with disposals. Int. J. Prod. Res. 22(1): 31-39.

Shapley, L., M. Shubik. 1969. Price strategy oligopoly under product variation. Cowles Foundation paper 291, reprinted from Kyklos 22(1).

Slikker, M., J. Fransoo, M. Wouters. 2005. Cooperation between multiple news vendors with transshipments. Eur. J. Oper. Res. 167(2): 370-380.

Tirole, J. 1988. The Theory of Industrial Organization. The MIT Press, Cambridge, MA.

Trivedi, M. 1998. Distribution channels: An extension of exclusive retailership. Manage. Sci. 44(7): 896-909. 
Tsai, J. F. 2007. An optimization approach for supply chain management models with quantity discount policy. Eur. J. Oper. Res. 177(2): 982-994.

Tsay, A. A., N. Agrawal. 2000. Channel dynamics under price and service competition. Manuf. Serv. Oper. Manage. 2(4): 372-391.

Vives, X. 1999. Oligopoly Pricing: Old Ideas and New Tools. The MIT Press, Cambridge, MA.

Weng, Z. K. 1995. Channel coordination and quantity discounts. Manage. Sci. 41(9): 1509-1522.

Wilcox, J. B., R. D. Howell, P. Kuzdrall, R. Britney. 1987. Price quantity discounts: Some implications for buyers and sellers. J. Mark. 51(3): 60-70.

Zentes, J., B. Swoboda. 2000. Allied groups on the road to complex networks. Technol. Soc. 22(1): 133-150.

\section{Supporting Information}

Additional supporting information may be found in the online version of this article:

\section{Appendix S1: Proofs.}

Please note: Wiley-Blackwell is not responsible for the content or functionality of any supporting materials supplied by the authors. Any queries (other than missing material) should be directed to the corresponding author for the article. 